\title{
Research on the Equalization of Public Cultural Services in Rural Areas of China: Current Situation, Problems and Countermeasures
}

\author{
Shaogang Liao", Danlei Yan', Ping Zhao \\ ${ }^{1}$ School of Public Finance and Public Administration, Jiangxi University of Finance and Economics, Nanchang, China \\ ${ }^{2}$ Modern Economics \& Management College, Jiangxi University of Finance and Economics, Nanchang, China
}

Email address:

liaoshaogang@163.com (Shaogang Liao)

To cite this article:

Shaogang Liao, Danlei Yan, Ping Zhao. Research on the Equalization of Public Cultural Services in Rural Areas of China: Current Situation, Problems and Countermeasures. Humanities and Social Sciences. Vol. 5, No. 4, 2017, pp. 138-144. doi: 10.11648/j.hss.20170504.12

Received: March 30, 2017; Accepted: May 9, 2017; Published: July 13, 2017

\begin{abstract}
Rural public cultural service is an important part of the construction of China's public cultural service system. With the continuous growth of China's economy, China's rural public cultural service system has made great achievements. However, the survey found that there are still some problems in China, such as the low input of public cultural services in rural areas, the shortage of total supply, the imbalance between supply and demand between the government and farmers, and weak hardware facilities. Therefore, to strengthen the construction of basic public cultural services in rural areas and promote the equalization of public cultural services in rural areas has become an urgent requirement for building a harmonious society in China.
\end{abstract}

Keywords: Rural Areas, Public Cultural Service, Equalization, Financial Input

\section{Introduction}

More than 30 years of reform and opening up, China's rapid economic development, the total economic output ranks the world's top second. However, the cultural construction has lagged behind the rapid development of the economy and the increasing level of material life. In particular, the overall development of rural public cultural services is not equal. The equalization of rural cultural services is an important part of the public cultural service system, which plays an important role in the development of urban and rural areas.

The rural cultural service mainly refers to the rural sports and entertainment services, scientific and technological knowledge services, cultural information services. The government departments involved in the rural cultural services are mainly the governments at all levels of culture, radio and television, science and technology and other relevant departments. ${ }^{[1]}$ The equalization of public cultural services in rural areas is an equal opportunity for farmers to enjoy public cultural services. At present, the equalization of public cultural services in rural areas of China has been a short board of public cultural service system, the supply and demand dislocation, the content of a single, lack of human resources, such as the status of non-equalization. This is not compatible with the rapid development of the economic society, to a certain extent, the development of the whole society. Therefore, the government departments should co-ordinate the development of urban and rural public culture, strengthen the urban culture to feed back to the countryside, to take effective measures to increase the intensity of improvement, to provide a strong support for China's better development of rural public culture.

\section{Analysis of China's Rural Public Cultural Services}

The equalization of rural public cultural services is not corresponding to the current economic and social development. The lag of rural cultural construction not only affects the overall development level of China's cultural industry, but also affects the development of rural social economy. The government's lack of financial investment in rural public cultural services, resulting in insufficient 
investment in rural cultural undertakings and serious imbalance in the proportion of the structure.

\subsection{Lack of Financial Investment of China's Cultural Undertakings}

For a long time in China, the cost of cultural undertakings accounted for the country's fiscal expenditure is about $0.38 \%$, accounted for GDP is about $0.08 \%$. As can be seen from table
1, 2010--2011 years of cultural undertakings is the lowest proportion of the national fiscal year, gradually stabilized after 2012, the proportion of GDP is steadily increasing year by year. It is understood that, 2004--2010, China's cultural industry added value of an average annual growth rate of over $23 \%$, in 2010 the national cultural industry added value exceeded 100 billion yuan, accounting for the proportion of GDP was $2.78 \%$.

Table 1. National cultural expenses accounted for the proportion of the country's total fiscal expenditure and GDP (unit: Billion, \%).

\begin{tabular}{lllll}
\hline Period & Cultural expenses & National fiscal expenditure & GDP & Proportion of national finance \\
\hline The 11th Five-Year & 1220.4 & 318672.05 & 3840184 & 0.38 \\
GDP
\end{tabular}

Source: «Statistical Yearbook of Chinese cultural relics», Beijing Library Press, 2015.

2000-2014, the national total output growth of $556.25 \%$, an average annual growth of $14.38 \%$. The science comprehensive total investment growth of $1580.57 \%$, an average annual increase of $22.46 \%$. The total amount of investment is higher than the national education and science comprehensive output, fiscal revenue and expenditure. But the cultural undertaking investment proportion is very little, accounting for about $10 \%$ of the proportion of expenditures. In recent years is less than $6 \%$, while the cultural industry investment accounted for the proportion of the state financial expenditure of about 2\%. (See Table 2)

Table 2. China's total investment in cultural growth and the background of the relationship between the situation since 2000.

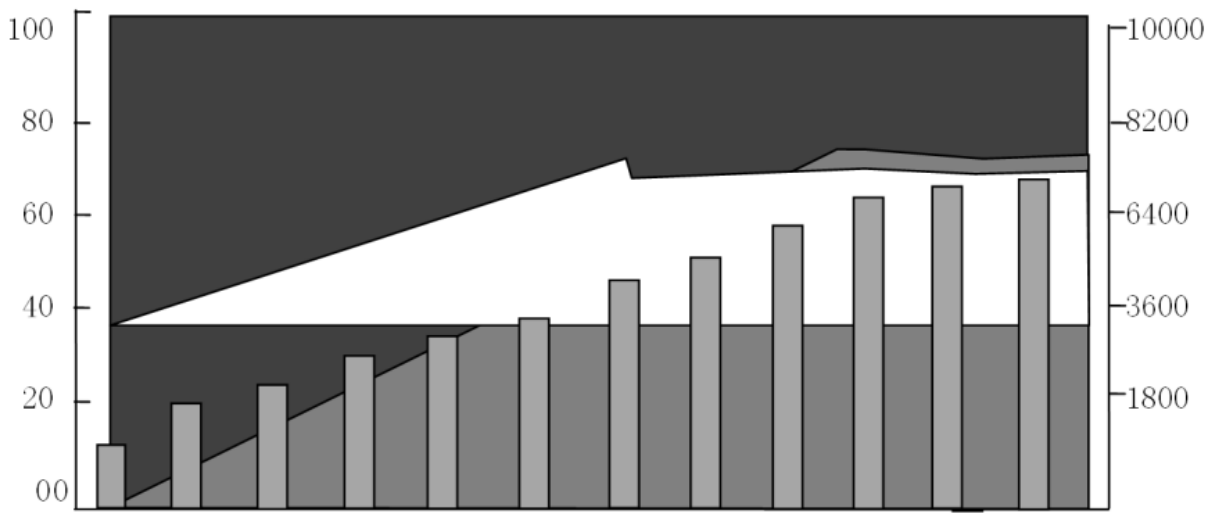

\begin{tabular}{|c|c|c|c|c|c|c|c|c|c|c|}
\hline & 2006 & 2007 & 2008 & 2009 & 2010 & 2011 & 2012 & 2013 & 2014 & 2015 \\
\hline$\square$ National fiscal expenditure & 40422 & 49781 & 62592 & 76299 & 89874 & 1092478 & 125953 & 139744 & 151662 & 175768 \\
\hline Dudget deficit & 1663 & 1540 & 1262 & 7782 & 6773 & 5373 & 8699 & 11002 & 11272 & 16200 \\
\hline$\square$ Investment in science and Technology & 6584 & 10895 & 13896 & 17176 & 20604 & 26755 & 32940 & 35366 & 38246 & 42935 \\
\hline$\square$ Cultural input & 841.9 & 898.6 & 1095.7 & 1393.1 & 1542.7 & 1893.4 & 2268.4 & 2544.4 & 2683 & 3067 \\
\hline$\square$ Other expenditure & 32997 & 37987 & 47600 & 57731 & 67727 & 80600 & 90745 & 102302 & 128138 & 147382 \\
\hline$\square$ Gross output value & 2163 & 2658 & 3140 & 3409 & 4015 & 4731 & 5195 & 5688 & 6013 & 6510 \\
\hline
\end{tabular}

Source: «"Cultural blue book" report on China's public cultural investment growth» (2015)

The total investment of national finance to cultural undertakings is less. From the statistical data, in 2000-2013, the total output value increased by $473.39 \%$, an average annual increase of $14.38 \%$. In $2006-2008,2010-2011,5$ annual growth of more than $15 \%$. Total fiscal revenue grew by 864.61 , the proportion of the national cultural expenses accounted for the national total fiscal expenditure was $0.41 \%$, the proportion of GDP accounted for $0.09 \%$. Especially in 1990 s, the proportion of cultural undertakings accounted for a lower proportion of GDP, only $0.06 \%$. 


\subsection{Uneven Development Between Regions, Uneven Allocation of Cultural Resources}

As can be seen from the data, there are big differences in the funding of cultural undertakings in different regions of
China, especially in the central region is particularly inadequate. From the country's per capita cultural differences in funding, the maximum has been Shanghai, Beijing, Tibet occupy the first place, while the minimum was occupied by Henan, Hebei and Anhui (See Table 3).

Table 3. Comparison and analysis of the per capita cultural undertakings and their differences in different regions of China (2004-2014) (Unit: Yuan)

\begin{tabular}{|c|c|c|c|c|c|c|c|}
\hline & 2004 & 2005 & 2006 & 2010 & 2012 & 2013 & 2014 \\
\hline Maximum & $\begin{array}{l}35.62 \\
\text { (Shanghai) }\end{array}$ & $\begin{array}{l}44.54 \\
\text { (Shanghai) }\end{array}$ & $\begin{array}{l}48.56 \\
\text { (Shanghai) }\end{array}$ & $\begin{array}{l}82.44 \\
\text { (Beijing) }\end{array}$ & $\begin{array}{l}120.65 \\
\text { (Shanghai) }\end{array}$ & $\begin{array}{l}121.96 \\
\text { (Shanghai) }\end{array}$ & $\begin{array}{l}160.06 \\
\text { (Tibet) }\end{array}$ \\
\hline Minimum & $\begin{array}{l}3.30 \\
\text { (Henan) }\end{array}$ & $\begin{array}{l}\text { 4. } 02 \\
\text { (Henan) }\end{array}$ & $\begin{array}{l}\text { 4. } 27 \\
\text { (Henan) }\end{array}$ & $\begin{array}{l}9.78 \\
\text { (Hebei) }\end{array}$ & $\begin{array}{l}15.08 \\
\text { (Anhui) }\end{array}$ & $\begin{array}{l}17.15 \\
\text { (Henan) }\end{array}$ & $\begin{array}{l}18.43 \\
\text { (Henan) }\end{array}$ \\
\hline Range & 32.32 & 40.52 & 44. 29 & 72.66 & 105.57 & 104.81 & 141.63 \\
\hline Average & 10. 6187 & 12. 6458 & 14. 2706 & 24.11 & 35.46 & 38.99 & 42.65 \\
\hline Standard & 8.4764 & 10.4122 & 10. 2649 & 20.067 & 27.306 & 27.88 & 34.69 \\
\hline
\end{tabular}

Source: Statistical Yearbook of Chinese cultural relics, Beijing Library Press, 2015.

In 2004, the national per capita cultural undertakings between Shanghai and Henan is very poor for 32.32 , to the year of 2014, the difference between Tibet and Henan actually reached 141.63. Thus, China's per capita funding gap is gradually expanding cultural undertakings. From the regional differences in the coefficient of view, in the span of $71.51 \%-83.23 \%$. In 2010, the coefficient of per capita cultural costs between the regions was as high as $83.23 \%$, and then gradually dropped to $71.51 \%$, which is the lowest point in nearly ten years (2013). In 2014, a rebound to $81.43 \%$. As can be seen from table 3, although China's Gene coefficient is small, but still showing an unstable change in 2010 reached nearly ten years since the peak of 0.1312 .

Table 4. Distribution of Chinese cultural undertakings according to urban and rural areas.

\begin{tabular}{|c|c|c|c|c|c|c|c|}
\hline & Years & 2000 & 2005 & 2010 & 2013 & 2014 & 2015 \\
\hline \multirow{6}{*}{ Total (Billion) } & Whole country & 63.16 & 133.82 & 323.06 & 530.49 & 583.44 & 682.97 \\
\hline & Above county & 46.33 & 98.12 & 206.65 & 272.67 & 292.12 & 352.84 \\
\hline & Below county & 16.87 & 35.70 & 116.41 & 257.82 & 291.32 & 330.13 \\
\hline & Eastern Region & 28.85 & 64.37 & 143.35 & 231.41 & 242.98 & 287.87 \\
\hline & Central region & 15.05 & 30.58 & 78.65 & 120.01 & 133.46 & 164.27 \\
\hline & Western Region & 13.70 & 27.56 & 85.78 & 152.16 & 171.15 & 193.87 \\
\hline \multirow{5}{*}{ Proportion } & Above county & 73.4 & 73.3 & 64.0 & 51.4 & 50.1 & 51.7 \\
\hline & Below county & 26.7 & 26.7 & 36.0 & 48.6 & 49.9 & 48.3 \\
\hline & Eastern Region & 45.7 & 48.1 & 44.4 & 43.6 & 41.6 & 42.1 \\
\hline & Central region & 23.8 & 22.9 & 24.3 & 22.6 & 22.9 & 24.1 \\
\hline & Western Region & 21.7 & 20.6 & 26.6 & 28.7 & 29.3 & 28.4 \\
\hline
\end{tabular}

In 2015, the cultural undertakings' institutions of the cultural units more than the county was 35.3 billion, accounted for $51.7 \%$, the cultural undertakings' institutions of the cultural units following the county was 33 billion, accounted for $48.3 \%$, Compared with the previous year, the proportion fell by $1.6 \%$. the cultural undertakings' institutions of the eastern region cultural units was 28.79 billion, compared with the previous year increased by $0.5 \%$. the central region cultural units was 16.42 billion, accounted for $24.1 \%$, which was increased by $1.2 \%$. the western region cultural units was 19.39 billion, accounted for $28.4 \%$, which was fell by $0.9 \%$. Cultural expenses accounted for the proportion of total fiscal expenditure was $0.16 \%$, compared with the previous year decreased by $0.01 \%$. The eastern region accounted for the largest proportion of the cost of cultural undertakings as $42.1 \%$, the central region was $24.1 \%$, lower than the eastern and western regions $28.4 \%$. The three areas are generally in an upward trend year by year. But in
2013 and 2014, the eastern and central regions declined compared with the previous year, respectively reduced by $0.8 \%, 2 \%$ and $1.7 \%, 0.3 \%$. The western region fell $0.9 \%$ in 2015. The difference between the East and the west, as well as the differences between urban and rural investment funds still need to be resolved.

\subsection{Rural Cultural Consumption in the Doldrums, the Type of Consumer Needs to Be Rich}

The per capita income and per capita consumption expenditure of urban residents are 3-4 times of rural residents. In recent years, the general trend of urban residents' cultural entertainment expenditure is still increasing, but rural residents continued to decline by $7.3 \%$ in $2005-2013$. The cultural and recreational consumption of rural residents has been in the doldrums for 8 years, which is one of the reasons for the equalization of public cultural services in rural areas. Since 2016, the income of rural residents grew faster than 
urban residents. Per capita consumption expenditure of urban residents was 23079, an nominal increase of $7.9 \%$ over the previous year, the actual growth was $5.7 \%$. Per capita consumption expenditure of rural residents 10130, an nominal growth of $9.8 \%$, the actual growth was $7.8 \%$. Rural residents per capita nominal growth rate and the actual growth rate was higher than urban residents $1.9 \%$ and $2.1 \%$, there is a rapid upward trend. But still need to increase rural grassroots public cultural service system financial investment.

\section{Analysis of the Causes of Non-equalization of Public Cultural Services in Rural Areas of China}

As the main undertaker of the rural public cultural service, the China government takes a top-down decision making in the content, distribution, quantity and quality of the rural public cultural service. This decision can meet the needs of the government in the national governance, but it is difficult to meet the needs of the spiritual and cultural level of the masses of farmers. China's rural area wide, large population base, resulting in the construction of public cultural service system is too decentralized. The Chinese government in terms of financial investment, still belongs to the urban bias model. The supply of basic public cultural services in rural areas is not enough, and there is a big gap between cities. The imbalance between supply and demand is caused by the imbalance between supply and demand, and the imbalance between supply and demand is difficult to reflect the real needs of farmers.

\subsection{Public Cultural Services in Rural Areas Attach Importance to "Send Culture", Despise "Culture Cultivation"}

China's rural areas rely mainly on township cultural stations to promote the development of cultural undertakings. However, due to the long-term accumulation of institutional constraints, these cultural stations did not assume public service organizations, but become a cultural management. The number of public culture provided by the government is small, most of them are still in order to meet the needs of certain specific festivals or investment and other government economic needs, and do not fully take into account the growing needs of the masses of farmers

At present, most of the grass-roots governments take the "send culture" to the countryside, and transfer the cultural resources directly to the grass roots. They ignore the local foundation of rural culture; ignore the culture of rooted planting. The folk culture and traditional culture was lack, which are the farmers' like. Government departments in the process of operation, the form is greater than the content, management and control is still the dominant ideology, which is seriously hindered the construction of rural public cultural service system, and eventually lead to serious dislocation of rural cultural services and farmers' needs.

\subsection{The Rural Public Cultural Service Resources Are Insufficient, the Farmer Participation Consciousness Is Weak}

At present, there is a great contradiction between the rigid supply and elastic demand of rural public cultural service. The main body of rural public cultural service is the government department, total funds inadequate investment, limited public cultural service facilities configuration is not balanced, leading to rural public cultural resources integration and utilization efficiency is not high, the coexistence of shortage and idle phenomenon. Government departments in the implementation of the film to the countryside and farmers and other projects to support the construction of the project, although there is a certain improvement in the status quo, a relatively rich cultural life of the peasants. However, due to the lack of follow-up maintenance funds, resource management is not standardized, so that the cultural needs of the masses of farmers is still difficult to meet. The lack of public cultural awareness of farmers, rural culture gradually eroded by some sub culture and anti culture erosion, local art and culture gradually disappear, this is not conducive to the development of physical and mental health of farmers and rural public cultural services, affect the social stability in rural areas.

\subsection{Low Performance of Rural Public Cultural Services}

Rural areas are backward in education, the number of rural public cultural professionals is insufficient, and the overall quality is not high. The special geographical position and the tight financial situation in rural areas are also difficult to attract professionals. Some of the cultural cadres in poor areas are also hold a number of jobs, scattered the forces of rural public cultural service system construction, seriously impact on the normal operation of grass-roots public cultural services. Due to the existence of market access restrictions, private capital is difficult to enter, lead to idle and waste of social and cultural resources. Therefore, the rural public cultural service efficiency is low, it is difficult to meet the needs of farmers.

In order to improve the construction of public cultural service in rural areas, we should not only increase the government investment, but also seek diversified cooperation. We should also fully consider the appropriateness of public cultural services. Service facilities, activities and others are content to really meet the needs of farmers or not. In order to better meet the needs of farmers' cultural life.

\section{China's Rural Public Cultural Service Responsibility and Supply Model}

With the rise of citizen's democratic consciousness, the desire of a large number of non-governmental organizations to participate in social management is becoming more and more intense, which gradually become the government departments to manage social affairs. In the construction of a new model of public cultural services in rural areas, through 
the introduction of social organization, formed a multi supply mode with the cooperation of government and social subjects, so as to provide better diversified rural public cultural services for farmers. Therefore, the supply of rural public cultural services has three modes of supply, including: government led supply model, collaborative supply model, and the main mode of social supply. [4]

\subsection{Government Led Supply Model}

For a long time, due to the limitations of market access barriers, the rural public cultural service itself has the characteristics of non exclusiveness and non competition, which lead the Chinese government has always been the main responsibility body and the main supply body. The number of other non-profit organizations is in a subordinate position, and is responsible for cooperation and assistance, which makes the government in the supply of low investment, lack of capacity and other issues.

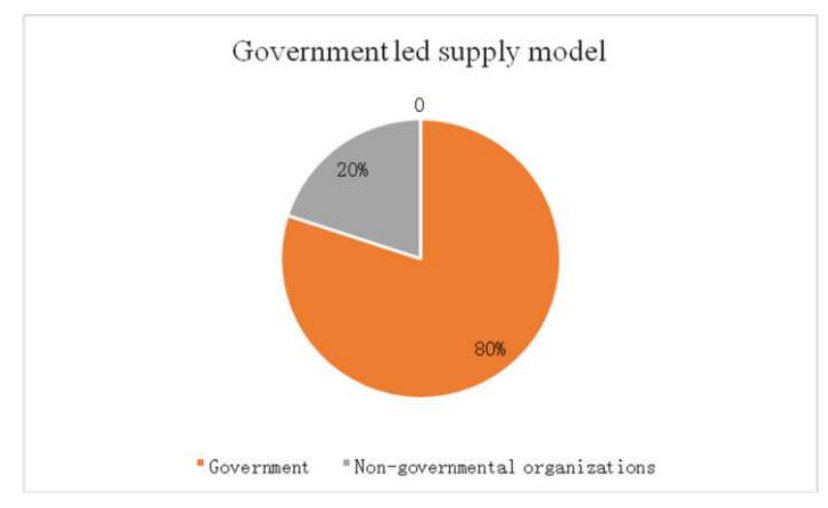

Figure 1. Government Led Supply Model.

\subsection{Cooperative Supply Model}

This is a win-win mode to adapt to the development of rural public cultural services, to better meet the needs of the masses of farmers and public cultural needs. It gets rid of the single supply mode of government monopoly, forms the mutual cooperation relationship, and reduces the financial burden of the government. Also through cooperation and cohesion of multi forces to achieve complementary advantages, innovative cultural service model, to better contribute to the construction of rural public cultural service system.

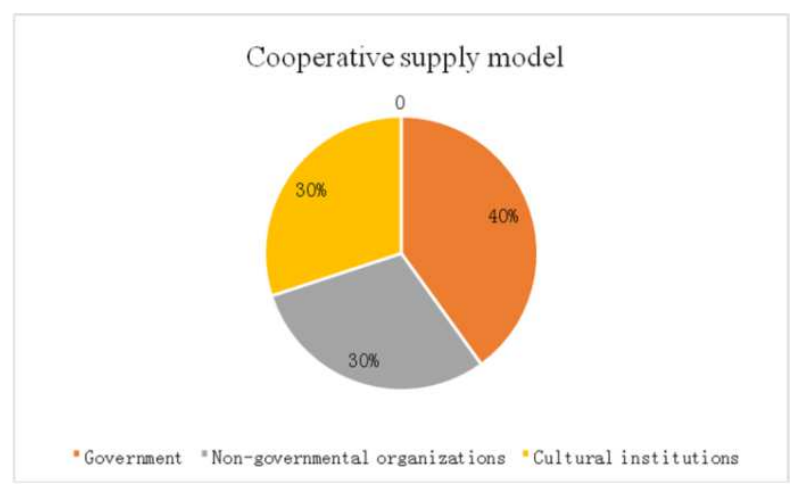

Figure 2. Cooperative Supply Model.

\subsection{Social Institutions Leading Supply}

In some rural areas where the government is difficult to reach, it is necessary to rely on social organizations to provide cultural services. Social organizations rooted in the community, understand the needs of the masses of farmers, to better reach the grassroots social resonance. Social organizations can fill the cultural capital and government facilities inadequate investment; secondly, to provide a large number of employment opportunities, to maintain social stability; finally, a large number of social organizations mutual cooperation can produce infinite value. Give people the power of innovation, in order to better enrich the cultural life of the masses of farmers and work together.

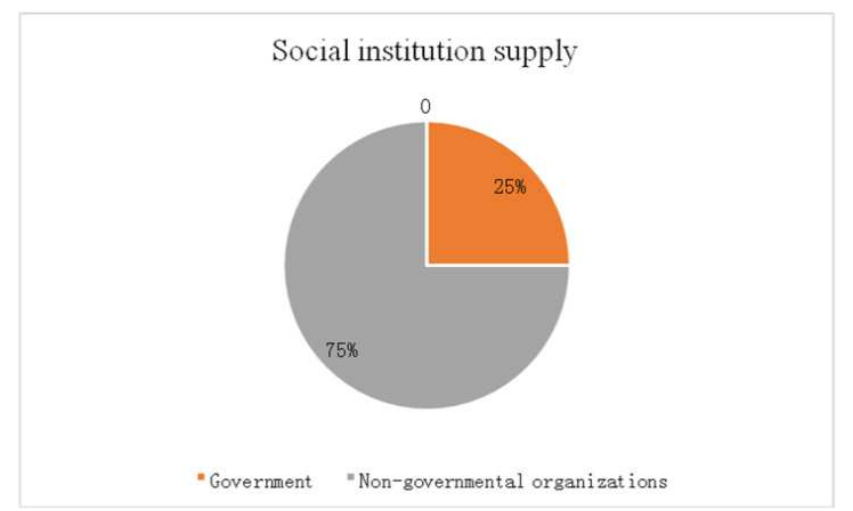

Figure 3. Social Institution Supply.

At present, the rural public cultural service system in China is in the period of cooperation between the government and the society. In the future, to fully understand the current situation of the region, to conduct a comprehensive analysis, make full use of local resources in rural areas, to form the government as the core, all kinds of social organizations diversified cooperation, create a new model of rural public cultural services.

\section{The Ways to Promote the Equalization of Basic Public Cultural Services in Rural Areas of China}

The equalization of public cultural services in rural areas is different from the equalization of urban and rural standards, which requires not only capital investment, facilities construction, but also a system innovation. Not the blind pursuit of absolute equality and the city, but to learn the differences of different regions exist. According to the person and local conditions to promote the equalization of public cultural services in rural. It not only enriches the cultural life of the peasants, but also reduces the pressure on the city.

\subsection{Improve the Financial System, Increase Investment in Cultural Undertakings}

Gradually establish and improve the public cultural capital investment mechanism of poor county to solve the 
problem of shortage of funds in poor areas. Strengthen the investment of rural public cultural services, and establish a stable financial guarantee mechanism of rural public cultural services. Improve the local legal system, management system and incentive mechanism to ensure that the annual budget to meet the actual needs, to ensure the unity of financial rights and powers. Fiscal transfer payment is an important economic means for the central government to carry out macroeconomic regulation and control. The equalization of public services across the country is also one of the basic objectives of the transfer payment. Promote the reform of fiscal transfer payment system, increase the scale and proportion of general transfer payments. Focus on the transfer payments increase in underdeveloped areas, narrowing the financial gap between regions, improve the utilization of investment funds.

\subsection{Broaden the Supply Channels of Rural Public Cultural Services}

The government's single leading cultural service supply model, hinder the development of rural public culture in terms of capital, resources and other aspects. We should innovate the way of rural public cultural service supply, management system and operation mechanism, actively encourage and attract social forces to participate in the construction of rural public cultural service system, to expand the effective supply of rural public cultural services, improve service quality and level. We should further decentralization, attract social capital and foreign invested enterprises in the field of public culture, construct the public cultural facilities, and provide public cultural services.

\subsection{Innovative Cultural Methods and Content, Awakening the Consciousness of Farmers}

According to local characteristics, and constantly expand and enrich the rural public cultural services. Through television, radio and entertainment activities, in the activities of scientific knowledge, agricultural knowledge, and actively encourage farmers to participate in rural cultural activities. Construction of a variety of rural cultural groups, to carry out a variety of cultural activities to stimulate the participation of farmers. Through the establishment of the dialogue mechanism between the government and the masses, to collect the cultural needs of farmers. So as to improve the ideological quality of the farmers, stimulate their awareness of the main body and the sense of participation.

\subsection{Strengthen the Construction of Rural Public Cultural Service Infrastructure}

Effectively increase the input of public cultural facilities in rural areas, and gradually improve the rural mass cultural venues and equipment. After meeting the material life of the peasants, we should fill the spiritual cultural life of the peasants. Through the construction of free cultural centers, libraries, museums, literary and artistic work stations and other infrastructure, to achieve the integration of rural cultural resources. With the development of the Internet, improve the construction of rural network facilities, to achieve a comprehensive coverage of rural public cultural network and use of the network to share cultural resources. We should actively develop a large number of outstanding local culture and folk culture in rural areas, and further build the project of material and non-material cultural characteristics. Actively guide the farmers to run their own culture, and truly become the protagonist of culture.

\subsection{Improve the Quality of Rural Public Cultural Service Personnel}

The quality construction of peasant masses is the foundation of rural public cultural service. Government departments should formulate preferential system to attract talented people, broaden channels to introduce cultural talent, and use the policies to retain local cultural elite talent. Encourage the establishment of relevant professional colleges and universities to expand the construction of rural public cultural services professional, service personnel training. Through the integration of training resources, improve the training mechanism, innovative training content, improve the culture of professional and continuing education and training. Give appropriate subsidies support to the institutions or personnel taht participate in the relevant rural cultural training. We will improve the mechanism of introduction, evaluation and training of cultural talents, develop a strict cultural assessment system, and set up a mechanism of rewards and punishments, subsidies and subsidies. Through the establishment of high-quality rural cultural talents, promote the construction of rural public cultural services, to better meet the cultural needs of farmers.

\section{Conclusion}

Promoting the equalization of public cultural services in rural areas is an important measure to promote social fairness and justice, and maintain social harmony and stability. But it is not easy and fast to achieve equalization. In this paper, through the study of the equalization of public services in rural areas in China, it is found that there are some problems, such as insufficient capital investment, unbalanced supply and demand structure, single supply channel and so on. And put forward improvement measures, such as, increase capital investment, improve the financial system reform, the establishment of multi cooperation supply mode, broaden the cultural supply system, strengthen the construction of cultural talents and improve the rural culture rural cadres quality. With the development of China's economy, the transformation of government functions, the deepening of the reform of the cultural system and the continuous improvement of the public finance system, under the joint efforts of the government, the society and the citizens, the goal of the equalization of basic public cultural services in China will be realized. 


\section{References}

[1] Wu Licai. Non equalization of rural cultural services and improvement measures [J]. Journal of Huazhong Normal University (Social Sciences Editions), 2008 (5): 10-17.

[2] Li Shaohui. The construction of rural public cultural service supply model [J]. Journal of National School of Administration, 2010 (2).

[3] Zhang Tianxue. China's current rural public cultural products supply system dilemma and Countermeasures [J]. Theory Monthly, 2011 (5).

[4] Zhang Qin. Research on promoting the construction of service oriented government and the equalization of basic public services [J]. Chinese Administration, 2009 (4).

[5] Fang Donglin. Public finance and equalization of basic public services [J]. Productivity research, 2011 (10).

[6] Xia Guofeng. Review on the research of public cultural service system [J]. Theory and Reform, 2011 (1).

[7] Kong Jing. Research on the ability of Chinese government to provide public cultural services [J]. Shandong Social Science, 2010 (3).

[8] Wang Xiaojie. An empirical analysis on the level of equalization of basic public cultural services in China -- Based on the comparison of data from 1999 to 2009 [J]. Financial research, 2012 (3).

[9] Li Namin. Analysis on regional difference of social public service in China [J]. economic geography, 2009 (6).

[10] Gen Xu. The plight of the supply of public services in rural culture and the choice of supply path [J]. Journal of University of Electronic Science and technology of China (Social Sciences Editions), 2012 (4).

[11] Wang Qian. Theoretical thinking on Equalization of urban and rural public services [J]. Journal of Central University of Finance and Economics, 2008 (8). 